\title{
DERIVED CHANGE-OF-STATE VERBS IN FRENCH: A CASE OF SEMANTIC EQUIVALENCE BETWEEN PREFIXES AND SUFFIXES*
}

\author{
CORALIE ROGER
}

\begin{abstract}
The paper reports on work carried out within Corbin's associative morphological model which postulates that form and meaning are deducible from one another. It is assumed that in French there is a neat semantic distribution between prefixes and suffixes because each affix is specified by its semantic instructional identity. If this is the case, then the affixes $a-$, en-, éand -is(er), -ifi(er) seem to constitute exceptions and represent semantic equivalence because each of them constructs deadjectival change of state verbs. In order to explain this apparent discrepancy, it is proposed here that the notion of "paradigm of morphological processes" is to be abandoned when characterizing the semantic scope of a rule and we should adopt the principle that one and only one affix corresponds to one and only one word formation rule.
\end{abstract}

\section{Introduction}

\subsection{Theoretical framework}

This paper reports on work carried out within the framework of Corbin's associative morphological model which postulates that form and meaning are deducible from one another.

With respect to the differences between prefixes and suffixes, it is assumed in Corbin $(1999,71)$ that "in a language like French, the global semantic distribution between prefixes and suffixes is quite clear". According to her, prefixes are devoted to expressing temporal and spatial relations, negation, deprivation and opposition, as well as quantification, whereas suffixes are used for notions like setting into relation, evaluation, collectivization, denomination of a process, denomination of a property, denomination of a state and denomination of an argument of the process like agent or instrument.

* This article is a quite modified version of a talk given at the 10th International Morphology Meeting, Budapest, in May 2002. I thank C. Lesselingue for her help with the English and G. Dal for useful discussions.

1216-8076/03/\$20.00 (c) 2003 Akadémiai Kiadó, Budapest 


\subsection{Data}

This semantic repartition between prefixes and suffixes suggests that prefixes and suffixes cannot compete with one another. But, if this is so, then the case of French derived change-of-state verbs is problematic: actually, those verbs are constructed both with prefixes and suffixes. For instance, appauvrir 'to impoverish', allonger 'to lengthen', enlaidir 'to make ugly', enivrer 'to make drunk', écourter 'to shorten', élargir 'to widen' are prefixed verbs whereas verbs like imperméabiliser 'to waterproof', moderniser 'to modernise', solidifier 'to solidify', rigidifier 'to make rigid' are suffixed ones. It is worth noting that Corbin does not mention these affixes in her article.

\subsection{The problem}

The question arises whether the affixes $a_{-}, e^{-}$, en- and -is(er), -ifi(er) operate within one Word Formation Rule (WFR) and constitute purely and simply an exception to the assumption of a neat semantic repartition between prefixes and suffixes ${ }^{1}$ or whether it is worth reconsidering them from another point of view in order to reassert the associative dimension of the model by stating that one meaning cannot be expressed by several forms.

Here, I will adopt the second position. First I will try to show the inadequacy of the traditional analysis of these affixal processes in terms of 'affixes constructing adjective-based change-of-state verbs', secondly I will propose an alternative analysis and thirdly, I discuss the theoretical consequences of my proposition.

\section{Against the traditional analysis of these affixal processes}

What I mean by "traditional analysis" is the first stage of Corbin's model. From (1987) to at least (1991), a WFR is defined:

- first by a very general meaning (change of state, relation, action) which is closely dependent upon a rigid structural frame (according to the base

1 We find this analysis for instance in Temple (1996, 298): "La RCM qui construit des verbes de changement d'état en français est un exemple de règle disposant d'un PM (paradigme morphologique, C.R.) étendu. Celui-ci comprend trois procédés morphologiques: la conversion (valid(er)), la préfixation (appauvr(ir)) et la suffixation (modernis(er)), la préfixation et la suffixation pouvant être réalisées au moyen de plusieurs affixes (cf. appauvrir/enrichir; moderniser/purifier)". 
categorial unicity principle, only one category of bases can be selected by a given affix which constructs only one category of words)

- secondly by all the morphological processes (which constitute the morphological paradigm ${ }^{2}$ of the WFR) which suit this semantico-structural definition.

Thus, in Corbin (1987), the affixes $a_{-}^{-}$, en-, é-, is(er) and -ifi(er) are gathered into a paradigm of morphological processes which depend on one WFR of 'change-of-state verbs' because they all construct adjective-based verbs whose semantic interpretation is 'make (more) Adj.'. I think such an analysis does not fit in with the principle of associativity since meaning appears to take precedence over forms.

My claim is that both the structural and the semantic analysis is somewhat wrong. I will start with the semantic issue and I will give some arguments against the traditional way of designating the semantic contribution of those affixes only as the construction of adjective-based change-of-state verbs.

\subsection{Against the traditional way of designating those affixes as change-of-state verb forming affixes}

My aim is to show that the semantic characterization of those affixes in terms of 'change of state' is not satisfactory because this semantic notion it is not contributed by them.

I do not deny the fact that verbs affixed by $a_{-}^{-}, e n-, e^{-},-i s(e r)$ or -ifi(er) are change of state verbs, I only claim that this semantic characterization is not satisfactory because it is not a morphologically distinctive one within an associative model.

Actually, I consider that the general meaning 'change-of-state' is the one and only interpretation allowed by the categorial relation $\mathrm{A}>\mathrm{V}$. Thus, we find it associated with verbs suffixed by -oy(er) like rougeoyer 'to glow red' as well as with converted verbs like mûrir 'to ripen'. Indeed, the notion of change can be associated with that of dynamicity. This means that adjectivebased verbs never carry a non-dynamic feature and so, they cannot be state verbs, in the terms of Vendler (1967). Anyway, it seems hard to imagine a morphological process of verbalization devoted to the construction of state

2 The notion of morphological paradigm of a WFR must not be understood the same way as what Bauer (1996) calls a derivational paradigm (like, for instance, the derivational paradigm of the word nation is nation, national, nationaliste, nationalité, nationaliser, nationalement $\}$ ) or be confused with inflexional paradigms (conjugation or declension). 
verbs: so, we can suppose that it is the status of derived verbs itself that restricts the possible range of interpretations.

I think the precise semantic content associated with this kind of change is due to the presence of the adjective in the structure of the verb. Adjectives can only refer to qualities or states whereas nouns have larger referential diversity and can denote places, artefacts, human beings, substances and so on. That is why, when the base of the verb is a noun, the kinds of changes involved are more diversified. For instance, denominal verbs suffixed by -is(er) allow for several interpretations: Plag (1999) identifies locative, ornative, resultative, inchoative, performative, and similative interpretations.

To sum up, in the lexicon, there is a class of verbs which refer to a change of state and this fact goes beyond the bounds of morphologically constructed meaning: some simple verbs (like casser 'to break') are also change-of-state verbs. It turns out that the semantic properties of the grammatical categories involved in deadjectival verbalisation are such that adjective-based verbs refer to a change-of-state process whatever affixes you find in them. We can note that verbs constructed with other affixes and showing other categorial relations than those considered here can also be said to be 'change-of-state verbs': for example, the notion of invalidation induced by verbs constructed with the prefix dé- (like décoiffer 'to dissarrange somebody's hair') or décoincer 'to unjam, loosen' also have something to do with the notion of 'change of state'.

Faced with this abundance of 'sorts of change-of-state verbs', it is hard to maintain the claim that this semantic characterization is contributed by the affixes $a_{-}$, en-, é-, -is(er), -ifi(er).

But, even if I may have shown that those derived verbs should not be semantically identified as 'change-of-state verbs', I am not yet able to provide another semantic analysis for them. My hypothesis is that this might be due to the fact that only adjective-based data were taken into account and that noun-based data were excluded. So, I will now provide some arguments against an adjective-based verb restriction.

\subsection{Against an adjective-based verb restriction}

\subsubsection{Theoretical argument}

Theoretically speaking, we can notice some changes in Corbin's model over time: if a WFR is always defined by the association between a certain structure and a certain meaning, in Corbin (1987) it is assumed that structures are characterized by base categorial unicity whereas this hypothesis is clearly 
abandoned in Corbin (1997) to be replaced by the notion of a certain semantic unicity among bases.

\subsubsection{Factual evidence}

\subsubsection{Generality of the double structure}

Empirically, we have some reasons to include noun-based verbs in our research: the first reason is the general nature of the double structure phenomenon which concerns every affixal process studied as can be seen in Table 1: all these affixes construct both noun-based and adjective-based verbs. ${ }^{3}$

Table 1

\begin{tabular}{|l|c|c|c|c|c|}
\cline { 2 - 6 } \multicolumn{1}{c|}{} & a- & en- & é- & -is(er) & -ifi(er) \\
\hline $\begin{array}{l}\text { NOUN-BASED } \\
\text { VERBS }\end{array}$ & acculturer & endimancher & émietter & hospitaliser & panifier \\
\hline $\begin{array}{l}\text { ADJECTIVE-BASED } \\
\text { VERBS }\end{array}$ & amincir & empirer & élargir & moderniser & fortifier \\
\hline
\end{tabular}

Then, if we consider that denominal data are not constructed by the same affixes as deadjectival ones, this entails that we analyse each affix operating on nouns as homophonous with the affix operating on adjectives. The observed regularity of the phenomenon seems to be incompatible with the accidental nature that characterizes homophony in general.

\subsubsection{Difficulty in identifying the category of the base}

In quite a large number of cases, it turns out to be rather difficult to decide whether a verb is noun-based or adjective-based. This is particularly the case for verbs derived with -is(er). For instance, how should we interpret a verb like ironiser: is it paraphrasable as se montrer ironique 'to be ironical' or as pratiquer l'ironie 'to use irony'?

Nevertheless, I do not adopt Plag's position that is in favour of an output oriented model in which "the syntactic category of the base is underspecified" $(1999,122)$. I only wish to emphasize that this difficulty in identifying the category of the base suggests that denominal and deadjectival constructions

${ }^{3}$ Glosses: acculturer (intégrer dans une nouvelle culture) 'to integrate into a new culture', amincir (rendre (plus) mince) 'to thin', endimancher (mettre ses habits du dimanche) 'to put on one's Sunday best', empirer (devenir pire) 'to get worse', émietter (mettre en miettes) 'to crumble', élargir (rendre (plus) large) 'to widen', hospitaliser (mettre dans un hôpital) 'to hospitalize', moderniser (rendre (plus) moderne) 'to modernize', panifier (transformer en pain) 'to make bread from', fortifier (rendre (plus) fort) 'to fortify'. 
are in such a semantically close relationship that it can be assumed that they are constructed by the same rule and involve the same affix.

\subsection{Summary}

None of the facts presented is sufficient in itself for us to draw any firm conclusion about whether the prefixes $a_{-}, e n-, e ́-$ and the suffixes -is(er) and -ifi(er) are semantically equivalent or not and how they eventually differ. They only show that their descriptions must be improved.

But the congruence of these facts leads us to the following supposition: if adjective-based data appear not to allow affixal semantic individuality to be easily apprehended, this may be explained by the fact that they constitute the central cases and that we must also examine denominal data in detail.

\section{An alternative to the traditional analysis}

\subsection{Introductory remarks}

\subsubsection{The "one affix $=$ one rule" hypothesis}

The analyses of the affixes $a_{-}$, en-, é-, -is(er) and -ifier I will propose mainly rest on the dismissal of the very general meanings that justified the existence of morphological paradigms in favour of an interest in affixal semantic individualization. ${ }^{4}$

Those proposed analyses about each affix plainly enforce the principle of associativity between form and meaning. The notion of morphological paradigm implies a kind of imbalance between affixal forms and affixal semantic roles since:

- on the one hand, if one affixal form exhibits "several meanings", then this form would be analyzed as a case of affixal homonymy;

- and on the other hand, if one meaning seems to be supported by several affixes, these affixes would be analyzed as synonymous affixes.

4 To illustrate this remark, let me emphasize the fact that, without calling into question the notion of paradigm itself, it is assumed by Corbin and others that this kind of gathering morphological processes into a paradigm glosses the semantic individuality of affixes which should be studied much more thoroughly (see, for instance, Corbin-Temple 1995).

Acta Linguistica Hungarica 50, 2003 
Here, my claim is that when dealing with several forms, the hypothesis that has to be made is that these affixes have several meanings.

\subsubsection{What method for what results?}

In Corbin's model, affixes differ from lexical units by the fact that affixes have instructional meanings while lexical units have referential ones.

Because of the absence - to my knowledge - of a typology of what the pertinent meanings associated with affixal semantics are, the results must be understood as intermediate between the current analysis in terms of "change of state' and real instructional meanings we wish to identify. The analyses I propose are based both on contemporary work taking place in other frameworks than the one retained in this paper and on a direct examination of the various verb corpora (with an examination of cases of doublets, considerations about the referential domains of the bases, productivity, production of neologisms and taking into account of the context, etc.) and introspection in order to synthesize all these pieces of information.

\subsection{Some results}

\subsubsection{About the suffixes -is(er) and -ifi(er)}

\subsubsection{Hypothesis about the semantic role of each suffix}

I will define the semantic scope of the rule to which they belong in terms of "assignment of properties" of the base word to one of the arguments of the constructed verbs:

- assignment of one or a subset of the properties of the base-word referent to the referent of one argument of the constructed verb in the case of -is(er) suffixation,

- assignment of the whole of the properties of the referent of the base-word to the referent of one argument of the constructed verb in the case of -ifi(er) constructions.

\subsubsection{Argument}

If my hypothesis is valid, then it can explain why -is(er) and -ifi(er) select different types of bases.

As a crucial example, let me emphasize the fact that only -is(er) selects proper nouns as bases (for example in maoser, platoniser, wagnériser). I think that this fact constitutes an argument supporting my hypothesis about the 
semantic specialization of, respectively, -is(er) and -ifi(er) especially since this structure is really very productive in synchrony: one can find numerous neologisms in the newspapers (I noted the following verbs, among others, with politicians' names as bases: arlettiser, balladuriser, bernadette-chiraquiser, douste-blaziser, hueïser, le péniser, pasquaïser, mégrétiser, tibériser, voynétiser).

Indeed, probably for pragmatic reasons, persons' names seem to be compatible only with one type of meaning, the one which is associated with -is(er) suffixation: NP-is(er) verbs mean that one argument of the verb shows one property of the NP such as the way of thinking, the way of writing, the way of singing, or whatever; with -ifi(er), the meaning should be a 'real conversion into NP' and it is just not conceptualizable.

Compare this with the fact that -ifier selects among its bases nouns of physicochemical elements. One can conceptualize a conversion 'for real' of one of these elements into another one: for instance spathifier 'to transform organic element into stony matter', or ethérifier 'to transform alcohol into ether'.

It is also noteworthy that -ifi(er) selects simple - morphologically simple and semantically simple -adjectives as bases: that is, adjectives referring to objective, material, concrete properties as in rigidifier 'to make rigid', solidifier 'to solidify'; whereas -is(er) mainly selects complex, suffixed adjectives, that is to say 'relational adjectives' like théatral: relatif au théatre 'theatrical: relative to the theatre' in théatraliser which are undetermined as to the content of the properties they denote.

It follows from these differences in the selection of the bases between the two suffixes that there is a related difference in the general interpretative orientation between the two kinds of verbs:

-is(er) constructs verbs which refer to reversible, partial, subjectively grasped processes while verbs constructed by -ifi(er) refer to final, complete, objectively apprehended changes. For instance, one can notice that -is(er) verbs can mostly be correlated with the domains of intellectual human activities $^{5}$ like religion (cf. islamiser, catholiciser, christianiser, judaïser and so on), politics (see maoïser, staliniser, fasciser, etc.), social organisation (communaliser, départementaliser, présidentialiser etc.), language (cf. argotiser, anagrammatiser, calembourdiser, 'to make puns' etc.) whereas those domains are absent from -ifi(er) constructions.

5 That is what I mean when I speak of "subjectively grasped processes".

Acta Linguistica Hungarica 50, 2003 


\subsubsection{About the prefixes $a$ - and $e n$ -}

\subsubsection{Hypothesis about the semantic role of each prefix}

My hypothesis can be formulated as follows: (i) the semantic role of $a$-consists in fitting the spatio-temporal circumstances of the denoted action in a certain punctual aspect; ${ }^{6}$ whereas (ii) the semantic role of en- consists in fitting the spatio-temporal features of the denoted action in a non-punctual dimension.

\subsubsection{Arguments}

There is some linguistic evidence that supports this proposition:

(a) In order to be in accordance with the different affixal semantic processes, different points of view about the referent of the base can be activated depending on affixes. For instance, concerning the nouns of parts of the body:

- in the case of $a$ - prefixation, body parts are considered as 'points of contact' (see: adosser 'to place something with its back against something', agenouiller 'to kneel down', s'accouder 'to lean on one's elbow');

- and in the case of en-prefixation, body parts are interpreted as surfaces of contact, as in endosser 'to put on', embrasser 'to embrace'.

The same difference is visible between atterrir 'to make a landfall' and enterrer 'to put in the earth'.

(b) We can see some interesting base selection phenomena; for instance, en- selects a lot of nouns of locking up places (for instance in encaserner 'to lodge into barracks', emprisonner 'to jail', encaver 'to put into a cellar', encager 'to cage up', etc.) and nouns of wrapping clothes (like in ensoutaner 'to cover with a soutane', emmailloter 'to wrap', encaper 'to cover with a cloak', etc.) whereas this kind of nouns are absent in the case of $a$ - prefixation. I think this is due to the semantic compatibility of this type of nouns with the notion of 'duration and completeness' induced by the semantic role of en-.

(c) Concerning adjective-based verbs prefixed with $a$-or en-, things seem less clear. Thus, I cannot really explain why in a couple of antonyms like pauvre/riche 'poor/rich', the first is prefixed with a-: appauvrir 'to impoverish' and the latter with en-: enrichir 'to make rich'. The same thing can be said for two semantically close verbs like empirer 'to get worse' and aggraver

6 According to Martin (2001), the semantic invariant of the verbs prefixed by $a$ - in Middle French is perfectivity which entails a resulting state for the argument affected by the process denoted by the verb. I do not consider that it is in contradiction to what I propose but I think this approach is syntactic and not semantic. 
'to aggravate'. Anyway, I think that a comparison between only two terms is not a linguistic method and that we must remain at the level of the system and take into account whole corpora and not some isolated data.

But, as $a$ - prefixation is in fact not much constrained, it allows us to include quite easily the majority of deadjectival verbs like annuler 'to nullify' or apurer 'to balance' and so on. They refer to processes in which the acquisition of the property of being nul 'null' or pur 'pure' must be perceived as punctual.

I also think I can retain the notions of non-punctuality - that is to say, durativity and/or completeness - as specifying the deadjectival prefixation with en-: this is clearly the case with verbs like ensanglanter 'to cover with blood', empuantir 'to stink out' and more generally verbs with adjectival bases denoting something diffuse, which overcomes the affected object like enhardir 'to make bolder', enivrer 'to make drunk'.

So, to conclude this point, I will assume that a unitary morphological treatment for each prefix considered is preferable to one based on homonymy.

\subsubsection{About the prefix é-}

\subsubsection{Hypothesis about the semantic role of $e^{-}$}

The semantic characterization I propose for $e^{-}$- is that $e^{-}$- induces in the semantic scope of the verb it derives the notion of a corruption of an initial state considered as the standard state.

\subsubsection{Argument}

With regard to é-prefixation, there is not much to be said. I have not found any particular restriction or selection among bases and it is also conspicuous that the meaning of the verbs is quite clear: for instance, écheveler 'to be disheveled' refers to the corruption of a standard state of what is supposed to be a normal hairstyle.

Aunargue Plénat (1997) propose, as semantic characterization, the notion of 'extraction/dissociation'. I think that the notion of corruption of a standard state better suits the data because it subsumes the two notions of extraction and dissociation (that can be considered as means of corruption) but it allows us to take into account some data that are neither relevant to the notion of dissociation nor to that of extraction (s'époumoner 'to shout oneself hoarse', for instance).

Note that here again a unitary treatment stands out quite easily. Indeed, most é- prefixed adjective-based verbs appear to fit our analysis: éborgner 'to 
poke somebody's eye out', émincer 'to slice thinly' clearly refer to a process which induces a non-standard state (respectively for a person or a vegetable).

See also the case of égayer 'to cheer up' which is employed, as confirmed by dictionaries, only in restricted contexts like égayer un séjour à l'hôpital 'to cheer up a stay in hospital', égayer son deuil 'to cheer up one's grief', égayer une pièce sombre 'to cheer up a dark room', contexts which do not refer to a stereotyped cheerful situation.

\subsection{Summary}

In the analyses I proposed above, with this destructuring of the initial paradigm, prefixes and suffixes are no longer in a situation of semantic competition. They theoretically cannot be in linguistic rivalry because of the principle I adopted that one affix defines one rule and I hope I have begun to demonstrate that they are really not so.

\section{Discussion}

The principle "one affix = one rule" implies change regarding the stratification of the processes of semantic specialization from the generality of the rule to the individual referential properties of each constructed verb.

In the framework integrating the notion of paradigm, the WFR is defined by a very general meaning strictly associated with the categorial relation between the base and the complex word, and is actualized by means of a certain number of morphological processes. The specialization then occurs depending on heterogeneous properties of the various affixes, but we do not know in what order and what is the relative place of each one of these properties (diachronic elements, productivity, phonetic and semantic constraints, etc.). To define the hierarchy of the pertinent properties will be one of the important tasks in future work. For instance, for the moment and at first sight, it is difficult to affirm that the three suffixes of nominalization -ment, -age, -tion have different semantic roles.

In the present proposition, each WFR is already defined by an affix with its very precise meaning ${ }^{7}$ (and all the other properties I already mentioned: diachrony, productivity, etc.) and, then, the referential specification can oc-

7 Meaning which must be in accordance with the general semantic properties of the kind of morphological process it belongs to: prefixation, suffixation, conversion, composition. 
cur: first according to the grammatical category of the base if the affix is compatible with several of them, and then to the semantico-referential properties of the base-word. This entails that, even if the category of the base does not appear in the first level of specification, we do not agree with Plag (1999)'s proposition of an unspecified input.

By this inversion, I do not mean that this is the way "linguistic things" are, I only mean that as a morphologist, I must first be interested in and orient my research towards the scope of the morphological processes themselves because the other dimensions do not concern me in the first place and may even hide the properly morphological component of the meaning. In fact, I believe that the lexicographic activity is too pregnant over the way we are used to viewing "word analyses": most morphologists aim to obtain something that looks like a definition (notably with their glossing activity). I think that if we have a suitable formalism (I am very far from having this ideal framework), we do not need such descriptions and that we can begin a morphological analysis of a complex word by the constructed meaning.

\section{Conclusion}

As a conclusion, I will summarize the results of this study. I gave a clearly negative answer to the question of whether prefixes and suffixes can be in a semantic equivalence and I hope that I have shown that the traditional gathering of the affixes $a_{-}, e n-, e^{-}$, is(er) and -ifi(er) into one morphological paradigm of constructing change-of-state verb processes constituted the wrong analysis, first because this was not a morphologically distinctive analysis, secondly because it did not take noun-based data into account, and thirdly because it concealed the semantic individuality of each affixal process.

But I must also emphasize the fact that the propositions I have made have theoretical consequences which go beyond the empirical facts. By rejecting the notion of morphological paradigm in favour of a real affixal identity, it is the whole hierarchy of the rules we can find in Corbin's work that is questioned.

\section{References}

Aunargue, Michel-Marc Plénat 1997. Manifestations morphophonogiques de la relation d'attachement habituel. Silexicales 1, Université de Lille III, C.N.R.S.

Bauer, Laurie 1996. Derivational paradigms. In: Geert Booij-Jaap van Marle (eds.) Yearbook of Morphology 1995, 243-56. Kluwer, Dordrecht.

Acta Linguistica Hungarica 50, 2003 
Corbin, Danièle 1987. Morphologie dérivationnelle et structuration du lexique. Max Niemeyer Verlag, Tübingen.

Corbin, Danièle 1991. La formation des mots: structures et interprétations. In: Lexique 10: $7-30$.

Corbin, Danièle 1997. La représentation d'une "famille" de mots dans le Dictionnaire dérivationnel du français et ses corrélats théoriques, méthodologiques et descriptifs. In: Recherches linguistiques de Vincennes 26: 5-38.

Corbin, Danièle 1999. Pour une théorie sémantique de la catégorisation affixale. In: Faits de langue 14: $65-77$.

Corbin, Danièle-Martine Temple 1995. Le monde des mots et des sens construits: catégories sémantiques, catégories référentielles. In: Cahiers de lexicologie 65: 5-28.

Martin, Robert 2001. Le préfixe $a$-/ad- en moyen français. In: Romania 119: 289-322.

Plag, Ingo 1999. Morphological productivity. Structural constraints in English derivation. Mouton de Gruyter, Berlin \& New York.

Temple, Martine 1996. Pour une sémantique des mots construits. Presses Universitaire du Septentrion, Villeneuve d'Ascq.

Vendler, Zenon 1967. Linguistics in philosophy. Cornell University Press, Ithaca NY.

Address of the author: Coralie Roger

35, rue Roland le Nestour

78300 Poissy, France

coralieroger@net-up.com 